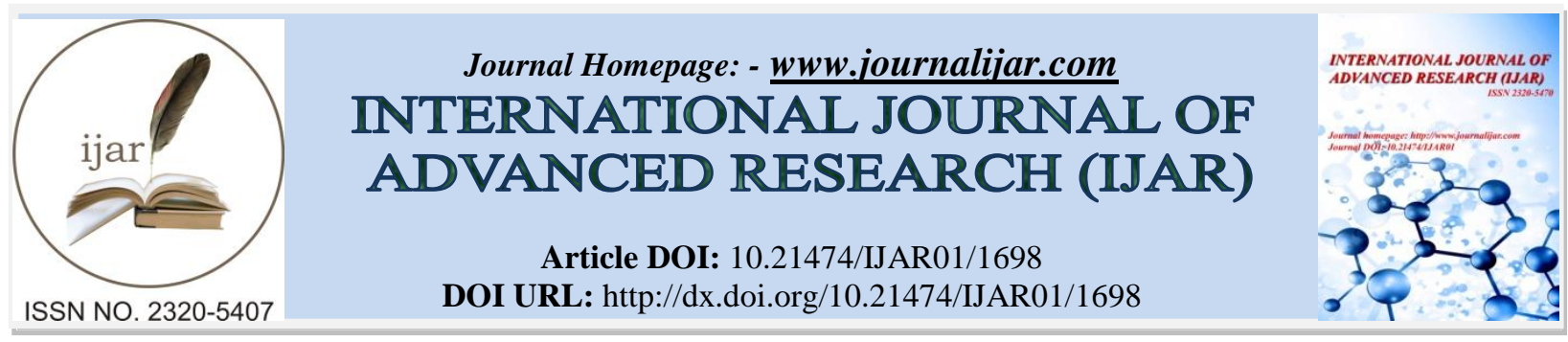

RESEARCH ARTICLE

\title{
SCIENTIFIC-THEORETICAL PROBLEMS OF DETERMINING THE PLACE OF THE RIGHTS TO PERSONAL CONFIDENTIAL INFORMATION IN THE SYSTEM OF CIVIL RIGHTS.
}

\section{Paluaniyazov Xalmuxammed}

$\mathrm{PhD}$, Associate Professor, senior science researcher at Tashkent State University of Law.

\section{Manuscript Info}

(.........................

Manuscript History

Received: 12 July 2016

Final Accepted: 19 August 2016

Published: September 2016

\section{Key words: -}

personal confidential information, object,

protection of personal confidential

information, the owner of the personal

confidential information

\section{Abstract}

This article discusses some of the problems of determining the place of the rights to personal confidential information in civil law, the powers of the holder of personal confidential information of its legal characteristics.

Personal confidential information is a set of relationships that develop between the state and citizens, between employer and employee, between a business entity and citizen, between the state and entrepreneurs, between the State and legal person in connection with the collection, storage and use of personal confidential information.

Personal confidential information is not included in the list of objects of civil rights. However, this does not mean that the information is not one of the objects of civil regulation. It can be said that the Civil Code contains the main constituent components of personal confidential information, it is the personality and dignity, business reputation, inviolability of private life, private and family secrets, etc., and you can say that these and other non-specified objects of civil rights united the concept of "other personal non-property rights." However, the uniqueness of personal confidential information as the intangible benefits is as follows. She - a purely personal and social good and perfect is inextricably linked with the personality of its owner, that is, personal confidential information is not alienated. For example, in the provision of training services or legal assistance to the owner of the personal confidential information, it does not lose. Therefore, the information may be classified as intangible benefits for compliance set by the Civil Code of the Republic of Uzbekistan (art. 99) features. Relationship, folding over the considered good, should be attributed to personal relations. Paradoxically in this situation is the fact that personal information is confidential in nature there is really immaterial good, but meaningful characterization of the latter differs fundamentally from the traditional civil law of this kind benefits (life, health, honor, dignity, and so on. D.). One of the main distinguishing features of personal confidential information from the other intangible benefits is the fact that a person as a complex self-organizing system is a potential source of personal confidential information.

Protection of personal confidential information and its use - is the basis of the mechanism of action of the holder in the field of non-property and property relations. As a result of the implementation of civil law is implemented the ability to independently perform actual and legal actions, competence requirements (possibility to demand from the obligated subject of the duties assigned to it), entitlement to the protection of (the possibility of using or requiring the use of state-of coercive measures in cases of violation of the privacy of confidential information). At the same 
time this subjective right corresponds to subjective responsibility as a measure of proper behavior. Such communication rights and responsibilities due to the interdependence of processes and implementation of the rights and obligations of enforcement mechanisms: a subjective right to the extent feasible, since it corresponds to the duties of others. This D.I. Meyer writes: "The concept of duty is subject to the concept of law. In fact, it seems above all a man with his free activity, known as the circle represented by this free activity, and have the right person. The concept of duty in the legal life is only in the recognition of the rights of others, and the most common duty is to respect the right. And so there is not even necessary, to define the science of law science of rights and responsibilities: this expression as it points to two distinct concepts, whereas the concept of the obligation already lies in the concept of law and deprived of independence ${ }^{1 "}$

Choosing a version of its behavior, the right holder has to match its actions, not only with their own interests, but also to the interests of other participants in the use of personal confidential information, for the holder shall take measures that third parties do not accidentally learned about personal confidential information.

In this regard, probably more correct to raise the question of what regulation around the objects of personal use and protection of confidential information should be included: personal non-property relations; property relations connected with personal relations. Property relations arising about the information, according to Part 1 of Art. 2 of the Civil Code of Uzbekistan are regulated by the rules of civil law and moral relations, non-proprietary, protected by them. The object of protection in this case is the right to privacy and the protection of private and confidential information and its use.

However, civil law as a science should not be limited to the description laid down in the Civil Code of the Republic of Uzbekistan. If personal confidential information has all the features of the subject of civil law, - they must be governed by them, regardless of whether they are connected with the property relations in the information sphere or not.

With properties, personal confidential information regardless of the carrier material, for easily converted from one form to another, moved from one material object to another. It is inexhaustible, that is actually inalienable. A citizen or journalist may remain the owner of the fixed media, regardless of the origin of proprietary rights the customer bases of data or newspapers.

In addition to all the above, personal confidential information may be subject to a mandatory relationship. For example, if the loan agreement, the parties voluntarily disclose all required personal information of a confidential nature, due to the fact that the lender has set such conditions (and, in turn, is still committed to provide protection against illegal use of confidential personal information of the client) who wants to get a loan. Here, in general, we are talking about information obligations, which took over the party and provide personal sensitive information. It is a civil matter, by virtue of which the holder is obliged on the basis of relevant information resources to provide personal sensitive information to the lender, and the lender has a prior obligation to ensure protection from illegal use and distribution of personal confidential information. Delivered so personal confidential information may be an element of the proper performance of the principal obligation to establish an insurance contract, the contract of medical services, loan agreement, agreement of legal services, and etc.

Continuing his arguments about the place of the personal rights of the confidential information in the system of civil rights, it should be noted that this is not a subjective right to an irreducible constituent elements of the whole, and is a set of capabilities (competences).

From the point of view of A.V. Malko, the citizen's right to privacy sensitive information may include powers to know about the establishment and operation of information systems, which in some degree affect the sphere of private life of the citizen; to give consent to the collection of personal information; the right to verify the accuracy of such information; to dispute inaccurate information as to the administrative and the judicial process; the right to a civil code (designation of a citizen in the respective information system) and other powers ${ }^{2}$ These powers largely cover the field of public law, but due to the fact that personal information confidential is a complex branch of law, it is protected as a criminal, administrative and civil law, too.

${ }^{1}$ D. Meyer Russian civil law. - Petrograd, 1914. P.9.

${ }^{2}$ Malko L.V. Citizen's right to information: the need for, nature, guarantees of Pravovedenie- // 1995.-№3. Р. 16. 
Great contribution to the study of the legal status of citizens as holders of personal confidential information made A.V.Malko and other authors ${ }^{3}$ in scientific works proposing measures to ensure the rights of citizens in the conditions of informatization of society. Despite their broad approach to the problem, the owner of the right to personal confidential information considered by them mainly through communication and interaction between the state and the citizen. Meanwhile, the use of personal confidential information is not restricted to vertical relationships of information. In the information field are also involved and other professional persons using personal confidential information (lawyers, insurance agents, notaries, employees of registry offices, auditors, appraisers, etc.), The experts of the professions that are in the interaction between a customer and are autonomous and equal rights. Here the customer or consumer corresponds to the obligation performer or vendor for the provision and use of personal confidential information.

In the civil turnover confidential personal information covers the relationship "the citizen and the citizen"; "Entrepreneur and the consumer"; "Legal entity and individual entrepreneur"; "Legal entity and its founder" and others.

Thus, between these entities are composed public attitudes about the use and protection of personal confidential information as provided by law or the execution of obligations to provide services? They involve at least two sides of the customer and the executor or seller and the consumer. At the same time its members can be quite a large number of persons connected rights and obligations. The essence of these relations is reflected in the fact that they represent the relative relationship between the individual - certain persons on the access and use of personal information confidential and its duty of protection, regulated by the norms of civil law. The system of civil legal relations in the field of personal confidential information is just as important as the moral and corporeal. A distinctive feature of the analyzed relationships from others is the fact that in them the rights and obligations between the parties to exchange information are added over the use of personal confidential information or her protection.

Competence to use personal confidential information in the law means meeting the needs of the owner of the personal confidential information. The informational activities of owners, it acts as a second type of entitlement, after the powers to obtain information. Information needs can be expressed in acquaintance or knowledge with personal confidential information (with the permission of the owner or in the public domain) on business partner or neighbor in the housing and so on. Satisfying this need is very important to choose the right partner (in business, his business reputation, etc.), or when the selected daughter is also used (with or without) questioned the neighbors, etc. If you deprive or restrict the rights of a resolution holder of personal confidential information or by the law, it may restrict or be an obstacle to the introduction of business, personal life, a job, and so, although in this case the blame is himself the owner of the personal confidential information and, accordingly, will himself be responsible.

The right to use the personal information is confidential application data, which are characterized as information associated with the semantic value of the various spheres of activity of the holder of personal confidential information. Exercise of the right of use enables the owner in its sole discretion limit the personal information, that is, the owner is given the discretion to decide to use personally sensitive information, avoid if a third party to this personal confidential information or vice versa to limit access to it, and the owner himself will bear the legal consequences of their decisions on the use of personal confidential information.

Competence dissemination of personal confidential information, based on the essence of art. 13 of the Law of Uzbekistan "On principles and guarantees of freedom of information" means the right to inform, to make transparent, to pass information to expand the circle of persons entitled to access to such information and make it widely known, accessible to many, obtaining information by citizens of other non-governmental sources of information (edition of the private media, the Internet, citizens and so on. d.). In other words, by the spread of personal confidential information refers to actions aimed at the transfer of information to a certain person or to become acquainted with such information the general public, including disclosure of such information in the media, the Internet, or providing access to this information in any other legal way.

Analysis of the content of the right to information and the characteristic type of behavior permitted his subject from the standpoint of the legislator allows us to formulate a model of the use and protection of personal confidential

\footnotetext{
${ }^{3}$ Information law: actual problems of the theory and practice. Monograph / Under editing I. Bachilo. M .: Yurlit
} 2009. 
information. As the holder of a subjective right, it includes the following positive powers: the right of access to information; the right to possession of the information; the right to use the information; the right to disseminate information; the right to limit access.

Due to the fact that the personal confidential information exclusively broad concept, formulated strictly and fairly universal model of the right to personal confidential information very difficult. Therefore, our offer is not certain. The emergence of other points of view on this issue - it is quite a positive thing, because "the constant struggle of opinion ensures the mobility of the legal form and the adequacy decisions" ${ }^{4}$ This seems to us; that this model is consistent with the legal nature of the use and protection of personal confidential information and the legitimate interests of the participants of the information relations in the sphere of use of personal confidential information.

Based on the foregoing, we can say that the term "personal sensitive information" we have determined in two ways: in the objective - as a set of legal norms that regulate social relations arising in connection with the creation, possession, use, distribution and restriction of access of personal confidential information, and in the subjective - as the totality of the powers and obligations of the owner of the personal confidential information. In this sense, personal confidential information - is provided by the owner of the opportunity to realize their potential in the search, possession, use, distribution and restriction of access to personal sensitive information in compliance with the legislation requirements.

Therefore, the implementation of the use of personal confidential information based on the following components of the title:

- The right to their own actions, which provides the holder of personal confidential information of possible choices of behavior when using personal confidential information. For example, the famous figure of popular culture may give or withhold its consent to the use of his personal appearance, or their voices in television advertising;

- The right to claim personal confidential information. For example, a customer in the obligation to provide information services may require the artist expeditious transfer of personal confidential information. A characteristic feature of subjective substantive rights is that it has a social character. In view of the above, the implementation of their abilities owners of the use and protection of personal confidential information can not be outside the civil regulation. Civil law can not leave this area of personality individualization beyond the scope of his study. This fact requires the development of a conceptual approach to the regulation of relations connected with the implementation of protection and use of personal confidential information holder, which would define the place and role of law in the civil law of the subject structure. However, a study of this type of individual citizens' rights shows that the rules governing the legal personality of citizens in civil legislation, are poor in content, are not complex and contradictory character in many ways.

Since this subjective right holder can not exist without the object to which it is directed, its legal nature is determined solely by the essence of appropriate personal confidential information. If personal confidential information is the subject of an information service, and the concomitant subjective right will be considered as a subjective property right, simulated special technician (when creating a database), attorney, auditor personal use of personal confidential information. If any private benefit in itself is not of material nature, for example, the right to business reputation, according to Art. 99 of the Civil Code of Uzbekistan, it will be called moral rights are not alienated from its owner. It follows that the "personal sensitive information" and "information" - the concept is certainly not identical: the first characterizes the personality of the citizens in the information activities; It acts as a second object, which is directed legal effect. Accordingly, the special features of social information are formalized and confer its own specific character design "personal sensitive information." Therefore purposeful meaning of the word "information" shows that everything that captures the "personal sensitive information," directed and performed for the sake of what is denoted by the term "information". Developing this idea, we can say that without that person's private life does not make sense. Personal confidential information does not mean the information itself; it is a subjective right of one of the participants in the information exchange. It expresses both individual and general social quality. Therefore, this right can be considered as an institution of civil law and as a means of expression of legal capacity the holder of personal confidential information. In this case, the observed two-way interaction of the inner world of man with the external information environment, and, as we know, every human life is a complex dialectical process that gives rise to the links between the following phenomena search, possession, use, distribution, and access restriction of personal confidential information, the content of which is concrete - historical determination.

\footnotetext{
${ }^{4}$ Dobrachev D.V. Opinion lawyer in modern civil law // the Legislation and economy-2004- № 1. P. 27.
} 
Depending on how the confidential personal information occurs, it is divided into the following types:

- The original personal confidential information, resulting from limited access rights holder;

- Derivative of personal confidential information arising from the right holder as a result of its activities (for information services), that is the creation of specific databases (containing personal confidential information) with the consent of the owner of the personal confidential information or by law.

This classification allows us to affirm that civil law norms can directly fix the use and protection of private and confidential information, or to provide information to participants by the relationship to determine the contract conditions of use and protection of personal confidential information.

In conclusion of our analysis, we note that the term "personal sensitive information" is not used in the doctrine of civil law and legislation. However, there is every reason for its application in the civil law literature and legislation. Personal confidential information as institutional education includes powers of access, possession, use, distribution and restricts access personal confidential information. The introduction of this term is quite logical, because the current civil legislation and other sources of law recognize the right of the holder to privacy of confidential information. The legislator recognizes the principles and limits of use and protection of personal confidential information. Information service is deemed an independent subject of obligations under the paid services.

Thus, the rules of the institution of civil law regulate relations in the absolute recognition of the human owner of the personal confidential information that assigns to all participants the obligation to comply with the information security requirements of the owner of the personal confidential information. In addition, the rules of protection and use of personal confidential information highlights include providing legal regulation of contractual and noncontractual use of personal confidential information.

In this case, personal confidential information exists in property relations on operational development and using personal confidential information, that is, to gather specific information on the holder to the person concerned (in case of a contract for the creation of a specific database, or collect data on potential partners from public databases of information or by law). The obligation to provide services may be deemed unexecuted or improperly executed on the ground, if the holders of rights have been violated in the privacy of confidential information and the customer became aware of this, he can recognize a contract to provide services to non-execution or executed improperly.

In addition, if the contract provided for private provision of services, the imposition of performance of the obligation by the debtor to a third party is prohibited. Such conditions are characteristic of the person - trust liabilities. It is found in the provision of services in which the contractor under the contract is the only citizens (lawyer - charge daffier, personal doctor, insurance agent, etc.). Competence specialist as a knowledge holder, skills, and other socially important information or - personal confidential information, to which it is for a certain time enjoyed, and knows all about the client (it can also be a valid reason) is very important when working with a client, and can act as one a prerequisite for long-term contact with the customer and be an additional guarantee of good use of personal confidential information. These circumstances suggest that the use and protection of personal confidential information exists objectively. Therefore, the law must provide legal protection of personal confidential information and its use in the civil law. All this is a necessary condition for the realization of objective standards in information activities for the holders of personal confidential information. 